\title{
The Influence of the Growth Environment on the Stability of a Drug Resistance Plasmid in Escherichia coli K12
}

\author{
By DIANNE GODWIN AND J. HOWARD SLATER \\ Department of Environmental Sciences, University of Warwick, Coventry CV4 $7 A L$
}

(Received 25 September 1978)

\begin{abstract}
Populations of Escherichia coli K12 containing the plasmid TP120 which coded for resistance to ampicillin, streptomycin, sulphonamide and tetracycline were grown in a chemostat under carbon-limited and phosphorus-limited conditions. With time, resistance to one or more of the drugs was lost, resulting in the production of mutant populations which were more competitive than the parent population. The resistance to tetracycline was always lost under both carbon and phosphorus limitations, but resistance to the other three drugs was lost only during phosphate-limited growth. Strains of $E$. coli which had lost resistance to one or more of the drugs were capable of higher maximum specific growth rates than the parent strain.
\end{abstract}

\section{INTRODUCTION}

Plasmids coding for drug resistances have been extensively investigated in terms of their biochemical, genetic and epidemiological properties but relatively little is known about the behaviour of plasmids and plasmid-carrying organisms under different environmental and physiological conditions. In particular, the effect of different growth environments and host growth rates on the survival and stability of extrachromosomal elements within a population has only recently been considered (Melling et al., 1977). Experiments with $\mathrm{R}$ factor-carrying Escherichia coli in the human gut have shown that the antibiotic-resistant population disappeared rapidly which suggested that the plasmid-containing population was less competitive than the resident populations (Anderson, 1974; Anderson, E. S., 1975). Fresh challenges with antibiotics resulted in the re-establishment of the resistant population (Anderson et al., 1973). Under non-challenge conditions it was suggested that the loss of the resistant population might be due to impaired growth rates of the plasmidcontaining population compared with the plasmid-minus population (Anderson, 1974) and/ or inhibition of plasmid transfer by bile salts, inert bacterial material and the density of the competitive organisms (Anderson, J. D., 1975). Conversely, in water supplies and raw sewage, drug-resistant coliforms showed a long-term survival and capacity to transfer the resistance factors in mixed populations (Grabow et al., 1974). Antibiotic-resistant Enterobacteriaceae occur at high frequencies in aquatic environments and it has been suggested that they survive well under these conditions (Smith, 1970; Freary et al., 1972; Hughes \& Meynell, 1975).

A number of closed culture studies have all shown that plasmid-containing microbial populations had lower maximum specific growth rates than plasmid-minus populations (Terawaki et al., 1968; Yokota et al., 1972; Grinsted \& Lacey, 1973; Lacey, 1975; Kayama \& Yara, 1975; Inselburg, 1978; Nakazawa, 1978). This strongly suggests that plasmidcontaining populations are at a competitive disadvantage under growth conditions where the characteristics coded for by the plasmid are not or do not need to be expressed. Melling et al. (1977), using chemostat continuous-flow culture techniques, showed that $E$. coli 
containing plasmid RP1 competed unsuccessfully against a plasmid-minus isogenic strain at submaximal growth rates. These results indicated that under appropriate growth conditions a competitive plasmid-minus population ought to be selected for from the original plasmid-containing parent population and in an open growth system replace the parent population. However, Melling et al. (1977) failed to select for a plasmid-minus population from a parent RP1-containing strain of $E$. coli under a number of different growth limitations, including carbon, magnesium and phosphate limitations. Conversely, an $\mathrm{F}^{\prime}$ laccarrying $E$. coli population growing under lactose-limited conditions in a chemostat was replaced after a short period by a more competitive $\mathrm{F}^{-}$strain derived from the parent strain (Slater \& Bull, 1978).

This study was undertaken to investigate the effects of various growth conditions (carbon and phosphorus limitation) and growth rates, using continuous-flow culture techniques, on the stability of a plasmid coding for resistance to ampicillin, streptomycin, sulphonamide and tetracycline in $E$. coli $\mathrm{K} 12$ in the absence of any of the drugs.

\section{METHODS}

Bacterial strains and plasmids. Escherichia coli $\mathrm{K}^{2} \mathrm{~F}^{-}$strain $1 \mathrm{R} 713$ was kindly supplied by $\mathrm{G}$. Willshaw (Central Public Health Laboratory, Colindale, London). This strain, designated K12(TP120), contained the plasmid TP120 (R46 or R Brighton) (Grindley et al., 1973) of compatibility group N which carried resistance to ampicillin (Ap), streptomycin $(\mathrm{Sm})$, sulphonamide $(\mathrm{Su})$ and tetracycline $(\mathrm{Tc})$ and was autotransferable. During the continuous-flow culture selection experiments, the following resistant strains were isolated: from a carbon-limited chemostat, K12(TP120A) (Ap, Sm, Su); and from phosphate-limited chemostats, K12(TP120B) (Sm, Su, Tc), K12(TP120C) (Ap, Sm, Su) and K12(TP120D) (Sm, Su). The nalidixic acid-resistant strain of $E$. coli $\mathrm{K} 12711 \mathrm{Nal}^{\mathbb{R}}$ [J62 nal-r, Harden \& Meynell (1972)] used as a recipient in transfer experiments was provided by K. P. Flint (University of Warwick).

Culture maintenance and growth. The strains of $E$. coli were maintained on nutrient agar slopes containing appropriate drugs at the following concentrations $\left(\mu \mathrm{g} \mathrm{ml}^{-1}\right)$ : ampicillin, 10 ; streptomycin, 10; sulphonamide, 50; tetracycline, 10. For closed culture growth, the organisms were grown in nutrient broth or the minimal medium described by Davis \& Mingioli (1950) containing $10 \%$ (w/v) glucose or Hershey's glucose mineral salts medium (Hershey, 1955). The cultures were incubated at $37^{\circ} \mathrm{C}$ with vigorous aeration and growth was measured by determining the absorbance $\left(A_{520}\right)$ in a Corning model 252 colorimeter. The Davis \& Mingioli minimal medium $\mathrm{pH} 7 \cdot 0$, supplemented with glucose to a growth-limiting concentration of $0 \cdot 2 \mathrm{~g} \mathrm{l}^{-1}$, was used for glucose-limited continuous-flow culture. For phosphate-limited chemostat growth, the organisms were grown in Hershey's glucose mineral salts medium (Hershey, 1955) at $\mathrm{pH} 7 \cdot 4$ with phosphate at $0.005 \mathrm{~g} \mathrm{l}^{-1}$. The continuous-flow culture vessels had a working volume of 11 and were agitated at 1000 rev. $\min ^{-1}$ with air supplied at $11 \mathrm{~min}^{-1}$; the growth temperature was $37^{\circ} \mathrm{C}$.

Procedure for selection and competition experiments in continuous-flow culture. For selection experiments, chemostats were inoculated with $10 \mathrm{ml}$ of an overnight culture of E. coli K12(TP120) and grown in batch culture for several hours in medium containing the drugs at the same concentration as the stock slopes. The fresh medium flow was initiated to give the required dilution rate and initially a steady state culture was established in the presence of the drugs. The medium was then changed to one lacking the drugs and samples were taken at $24 \mathrm{~h}$ intervals for viable organism determination. After appropriate dilution in $0.1 \mathrm{M}-\mathrm{KH}_{2} \mathrm{PO}_{4} / \mathrm{KOH}$ buffer $\mathrm{pH} 7.0$ at $37^{\circ} \mathrm{C}, 0.1 \mathrm{ml}$ samples were plated on nutrient agar plates, glucose minimal medium agar plates and glucose minimal medium agar plates containing, separately, at $60 \%$ minimal inhibitory concentration $\left(\mu \mathrm{g} \mathrm{ml}^{-1}\right)$ : ampicillin, 50; streptomycin, 10 ; sulphonamide, 10 ; or tetracycline, 25 . Viable counts were determined after $2 \mathrm{~d}$ at $37^{\circ} \mathrm{C}$.

Two-membered mixed culture competition experiments were performed with $E$. coli K12(TP120) and E. coli K12(TP120A). Separate overnight cultures grown in glucose mineral salts medium were simultaneously inoculated into a glucose-limited chemostat to give approximately equal population densities. After a period of closed culture growth, to overcome problems associated with variable lag phases and to ensure that both populations were growing exponentially, the fresh medium flow was initiated to give the selected dilution rate, ranging from 0.10 to $0.35 \mathrm{~h}^{-1}$. Samples were taken at 3 to $4 \mathrm{~h}$ intervals for viable organism determination by plating on nutrient agar and nutrient agar supplemented with tetracycline at $25 \mu \mathrm{g} \mathrm{ml}^{-1}$. Viable counts were determined after $2 \mathrm{~d}$ at $37^{\circ} \mathrm{C}$. The specific growth rate of the uncompetitive population, $\mu_{1}$, was calculated in two ways. Firstly, using a modified washout growth rate equation due to Jannasch (1969): 


$$
\mu_{1}=\frac{\ln x_{\mathrm{t}}-\ln x_{0}}{\left(t_{2}-t_{1}\right)}+D
$$

where $x_{0}$ is the initial uncompetitive population size at time $t_{1}, x_{\mathrm{t}}$ is the final uncompetitive population size at time $t_{2}$ and $D$ is the dilution rate maintained for the duration of the experiment. Secondly, the difference in the specific growth rates of the two competing populations was calculated from:

$$
\left(\mu_{1}-\mu_{2}\right)=\frac{\ln R_{t}-\ln R_{0}}{\left(t_{2}-t_{1}\right)}
$$

where $R_{0}$ is the initial ratio of the competitive population to the uncompetitive population at time $t_{1}, R_{\mathrm{t}}$ is the final ratio of the two populations at time $t_{2}, \mu_{1}$ is the specific growth rate of the uncompetitive population $x_{1}$ and $\mu_{2}$ is the specific growth rate of the competitive population $x_{2}$. When $x_{2} \gg x_{1}$, then in chemostat culture $\mu_{2}=D$ (Slater \& Bull, 1978) and so:

$$
\mu_{1}=\frac{\ln R_{\mathrm{t}}-\ln R_{0}}{\left(t_{2}-t_{1}\right)}+D
$$

Isolation of plasmid DNA. Plasmid DNA was isolated by a dye buoyant caesium chloride density gradient centrifugation method (Palchaudhuri \& Chakrabarty, 1976) as modified by K. G. Hardy (University of Kent, personal communication).

Conjugation. The maintenance, or otherwise, of an autotransferable plasmid in the various isolates obtained by continuous-flow culture selection was demonstrated by showing its potential to transfer to a plasmid-minus recipient (Dennison \& Baumberg, 1975). Cultures of the recipient were grown in nutrient

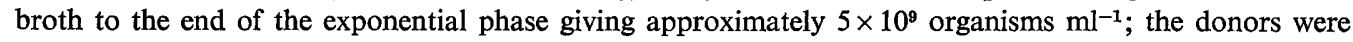
grown to mid-exponential phase in either nutrient broth or the minimal media, giving approximately $2 \times 10^{8}$ organisms $\mathrm{ml}^{-1}$. Recipient $E$. coli $\mathrm{Nal}^{\mathrm{R}}(0 \cdot 1 \mathrm{ml})$ was spread on nutrient agar plates supplemented with $10 \mu \mathrm{g}$ ampicillin $\mathrm{ml}^{-1}$ or $10 \mu \mathrm{g}$ sulphonamide $\mathrm{ml}^{-1}$. The donor strains were serially diluted separately to $10^{-6}$ dilution and $0.02 \mathrm{ml}$ of each dilution was inoculated dropwise on to the surface of the plates spread with $E$. coli Nal ${ }^{R}$. The plates were incubated for $18 \mathrm{~h}$ at $37^{\circ} \mathrm{C}$ and the number of colonies growing at a suitable dilution were counted. The colonies represented nalidixic acid-resistant $E$. coli organisms which had received by conjugation a plasmid carrying ampicillin or sulphonamide resistance (transconjugants), and the frequency of transfer was expressed as the percentage of transconjugants to total donor organisms. For each conjugation experiment, a number of transconjugant colonies were transferred to a range of media supplemented separately with the four drugs to check for the concomitant transfer of all the expected resistance markers.

\section{RESULTS}

\section{Plasmid stability and strain selection}

The stability of populations of $E$. coli containing plasmid TP120 was examined under glucose-limited and phosphate-limited conditions at dilution rates between $0 \cdot 10$ and $0.35 \mathrm{~h}^{-1}$. In all experiments, at least one of the drug resistance markers was eventually eliminated from the population. However, the pattern of loss of markers from glucoselimited cultures was different from that from phosphorus-limited cultures. In all the glucoselimited cultures only the resistance to tetracycline was lost. In the experiment shown in Fig. 1, the parent population, as measured by the loss of tetracycline resistance, declined by a factor of more than $10^{6}$ between 500 and $800 \mathrm{~h}$ after changing to drug-free medium; it was replaced by a second population, $E$. coli $\mathrm{K} 12(\mathrm{TP} 120 \mathrm{~A})$, lacking resistance to tetracycline but retaining resistance to ampicillin, streptomycin and sulphonamide. For a further $1000 \mathrm{~h}$ of growth there was continuous presence of the parent population at concentrations varying between 10 and $10^{3}$ organisms $\mathrm{ml}^{-1}$ (up to $0.0001 \%$ of the total population). During this time no additional changes in the dominant population were apparent and there was no further loss of drug resistance markers. The dominant population from the selection experiment at $D=0 \cdot 10 \mathrm{~h}^{-1}, E$. coli $\mathrm{K} 12$ (TP120A), contained a plasmid, as shown by density gradient centrifugation following cell lysis, and retained the capacity to transfer a plasmid carrying resistance to ampicillin, streptomycin and sulphonamide (Table 1). The other strains showing similar phenotypes to E. coli K12(TP120A) that were isolated from selection experiments at higher dilution rates were not analysed further. 


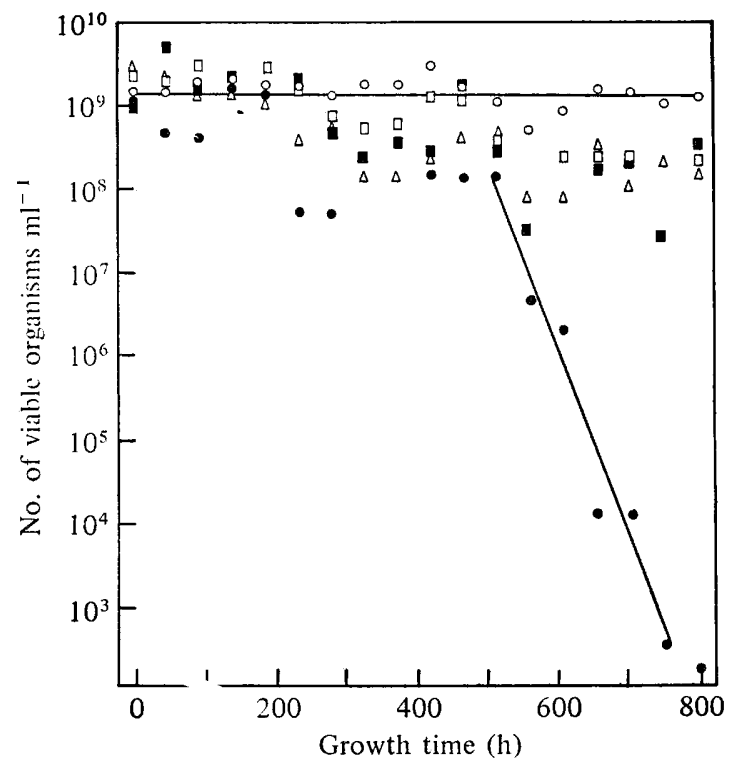

Fig. 1. The growth of $E$. coli $\mathrm{K} 12(\mathrm{TP} 120)$ in a glucose-limited chemostat at a dilution rate of $0 \cdot 10 \mathrm{~h}^{-1}$ illustrating the displacement of the tetracycline resistance marker (and hence the parent population) and the domination of a derivative strain [E. coli K12(TP120A)] resistant to ampicillin, streptomycin and sulphonamide but sensitive to tetracycline. Time 0 is the time at which drug-free medium flow was started. Total number of viable organisms $(O)$, and number of viable organisms resistant to tetracycline $(\odot)$, ampicillin $(\square)$, streptomycin $(\mathbf{\square})$ and sulphonamide $(\triangle)$.

Table 1. Presence of plasmids in selected E. coli $\mathrm{K} 12$ strains and frequencies of plasmid transfer

The presence of plasmids was examined by density gradient centrifugation. Plasmid transfer ability was tested with the plasmid-minus recipient $E$. coli $\mathrm{K} 12 \mathrm{Nal}^{\mathrm{R}}$. Strains were derived from continuous-flow selection experiments at a dilution rate of $0 \cdot 10 \mathrm{~h}^{\mathbf{- 1}}$ under carbon-limited conditions (a) or phosphorus-limited conditions (b).

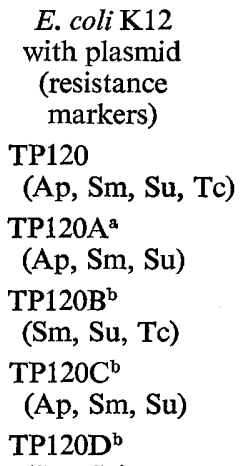

(Sm, Su)

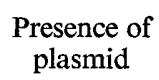

$+$

$+$

$+$

$+$

$+$

$10^{3} \times$

Percentage frequency of transfer of markers

$\overbrace{\begin{array}{c}\text { Nutrient } \\ \text { broth }\end{array}}^{\begin{array}{c}\text { Davis \& Mingioli } \\ \text { defined } \\ \text { medium }\end{array}} \begin{gathered}\begin{array}{c}\text { Hershey } \\ \text { defined } \\ \text { medium }\end{array} \\ \text { medium }\end{gathered}$

A more complex pattern of loss of drug resistance markers associated with an increase in parent strain instability was observed in the phosphate-limited selection experiments. In common with selection under carbon-limited conditions, the tetracycline marker was routinely lost from steady state cultures at similar washout rates, but it was never completely eliminated and replaced by a more competitive tetracycline-minus mutant as might be expected theoretically. In only one instance under phosphate-limited conditions at 


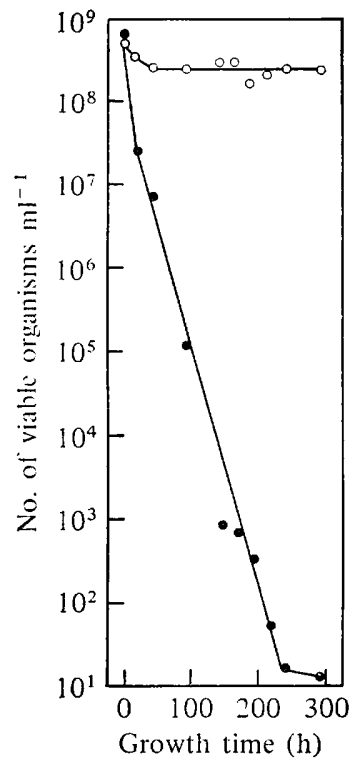

Fig. 2

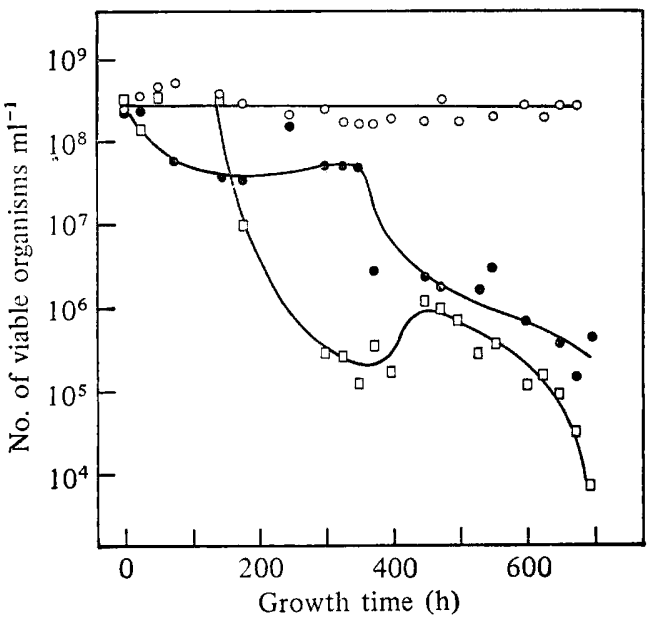

Fig. 3

Fig. 2. The growth of $E$. coli K12(TP120) in a phosphate-limited chemostat at a dilution rate of $0 \cdot 10 \mathrm{~h}^{-1}$ showing the loss of the tetracycline resistance marker and hence the parent population. The replacement population [E. coli $\mathrm{K} 12(\mathrm{TP} 120 \mathrm{C})]$ was resistant to ampicillin, streptomycin and sulphonamide, and all three resistances were individually present at above $10^{8}$ resistant organisms $\mathrm{ml}^{-1}$ for the duration of the experiment. Time 0 is the time at which drug-free medium flow was started. Total number of viable organisms $(O)$, and number of viable organisms resistant to tetracycline (O).

Fig. 3. The growth of $E$. coli K12(TP120) in a phosphate-limited chemostat at a dilution rate of $0 \cdot 35 \mathrm{~h}^{-1}$ showing the loss of ampicillin and tetracycline resistance markers. Time 0 is the time at which drug-free medium flow was started. Total number of viable organisms $(O)$, and number of viable organisms resistant to tetracycline (O) and ampicillin ( $\square$ ).

$D=0 \cdot 10 \mathrm{~h}^{-1}$ was tetracycline resistance the sole marker lost (Fig. 2). In this experiment the original population resistant to the four drugs persisted at a level of approximately 10 organisms $\mathrm{ml}^{-1}$ in a total population of $4 \times 10^{8} \mathrm{E}$. coli $\mathrm{K} 12(\mathrm{TP} 120 \mathrm{C})$ organisms $\mathrm{ml}^{-1}$. Throughout the experiment all the other three drug resistances were individually shown to be present at concentrations above $10^{8}$ resistant organisms $\mathrm{ml}^{-1}$ demonstrating that the disappearance of tetracycline resistance reflected only the washout of the parent population. Unlike the loss of tetracycline-resistant organisms under glucose-limited conditions, however, with phosphate as the growth-limiting nutrient the disappearance of the tetracycline resistance marker usually began soon after the removal of the drugs from the growth environment (Fig. 2), although this was not always the case (Fig. 3). A number of different selection experiments yielded dominant derivative strains with the same phenotype as $E$. coli $\mathrm{K} 12(\mathrm{TP} 120 \mathrm{C})$, but only the strain isolated at $D=0 \cdot 10 \mathrm{~h}^{-1}$ was analysed and shown to contain a plasmid (Table 1). Unlike the comparable strain isolated from carbon-induced selection [E. coli $\mathrm{K} 12(\mathrm{TP} 120 \mathrm{~A})]$, numerous attempts failed to demonstrate any retention of the capacity to transfer the derived plasmid into the recipient strain (Table 1).

An important difference between carbon-limited and phosphorus-limited stability and selection experiments (with the single exception of the phosphate-limited selection experiment just mentioned) was that under phosphate-limited conditions drug resistance markers other than tetracycline were also lost which led to the selection of different dominant populations with various plasmid genotypes in different experiments. Furthermore, these experiments produced mixed cultures with two or more different strains containing various 
Table 2. Maximum specific growth rates for selected $E$. coli $\mathrm{K} 12$ strains carrying various drug resistance markers (or none) in closed culture on defined media

Strains were derived from continuous-flow selection experiments at a dilution rate of $0 \cdot 10 \mathrm{~h}^{-1}$ under carbon-limited conditions (a) or phosphorus-limited conditions (b).

$E$. coli $\mathrm{K} 12$
with plasmid
(resistance
markers)
TP120
(Ap, Sm, Su, Tc)
TP120A
(Ap, Sm, Su)
TP120B
(Sm, Su, Tc)
TP120C
(Ap, Sm, Su)
TP120D
(Sm, Su)
No plasmid

Maximum specific growth rate,

\begin{tabular}{|c|c|c|}
\hline \multicolumn{2}{|c|}{$\mu_{\max }\left(\mathrm{h}^{-1}\right)$} & \multirow[b]{2}{*}{$\begin{array}{l}\text { Average percentage } \\
\text { decrease of parent } \\
\mu_{\max } \text { compared with } \\
\text { mutant strains }\end{array}$} \\
\hline $\begin{array}{l}\text { Davis \& Mingioli } \\
\text { defined } \\
\text { medium }\end{array}$ & $\begin{array}{l}\text { Hershey } \\
\text { defined } \\
\text { medium }\end{array}$ & \\
\hline
\end{tabular}

$\begin{array}{lll}0.40 & 0.39 & - \\ 0.56 & 0.50 & 25 \\ 0.46 & 0.60 & 25 \\ 0.57 & 0.48 & 24 \\ 0.47 & 0.56 & 23 \\ 0.69 & 0.90 & 50\end{array}$

combinations of drug resistance markers. For example, in one selection at $D=0 \cdot 10 \mathrm{~h}^{-1}$, after $300 \mathrm{~h}$ growth in drug-free medium the culture was dominated by $E$. coli K12(TP120D) which carried resistance only to sulphonamide and streptomycin and contained a nontransferable plasmid (Table 1). After this period of growth the culture also contained a population only lacking resistance to tetracycline [that is, showing the same phenotype as E. coli $\mathrm{K} 12(\mathrm{TP} 120 \mathrm{~A})$ and $\mathrm{K} 12(\mathrm{TP} 120 \mathrm{C})]$ at $0.001 \%$ of the total population and a second population lacking resistance to ampicillin at $1 \%$ of the total population. The latter strain was isolated, designated $E$. coli $\mathrm{K} 12$ (TP120B) and shown to carry resistance to streptomycin, sulphonamide and tetracycline and to contain a transferable plasmid (Table 1).

Another feature of populations growing with phosphate as the limiting nutrient was that the washout curves for the loss of individual resistance markers rarely followed the anticipated washout kinetics (Fig. 3). The change in the logarithm of the population(s) with resistance to a specific drug was usually non-linear, exhibited plateau periods and occasionally short phases of transient increase in drug resistance before washout continued (Fig. 3).

Competition between the parent organism, E. coli $\mathrm{K} 12(\mathrm{TP} 120)(\mathrm{Ap}, \mathrm{Sm}, \mathrm{Su}, \mathrm{Tc}$ ), and a tetracycline-sensitive organism, $E$. coli $\mathrm{K} 12(\mathrm{TP} 120 \mathrm{~A})(\mathrm{Ap}, \mathrm{Sm}, \mathrm{Su})$, in open culture

The continuous-flow culture stability experiments showed that, particularly under phosphate-limited growth conditions, it was possible to select for mutant strains carrying decreased numbers of drug resistance markers. Indeed, the final stage of one phosphatelimited stability experiment yielded an organism lacking resistance to all four of the drugs and which could not be shown to contain a plasmid. Furthermore, in prolonged selection experiments, the derivative strains that were resistant to three or less of the drugs tended to dominate the original organism suggesting that under the prevailing growth conditions these strains had a selective growth advantage. Closed culture experiments (Table 2) showed that the four mutant strains carrying plasmids coding for resistance to two or three drugs were capable of faster growth rates with maximum specific growth rates $\left(\mu_{\max }\right)$ approximately $30 \%$ greater than the parent strain. This trend was continued by the plasmid-minus strain whose $\mu_{\max }$ value was greater than those of the plasmid-containing mutants and twice the $\mu_{\max }$ of $E$. coli K12(TP120). However, these differences may not be 


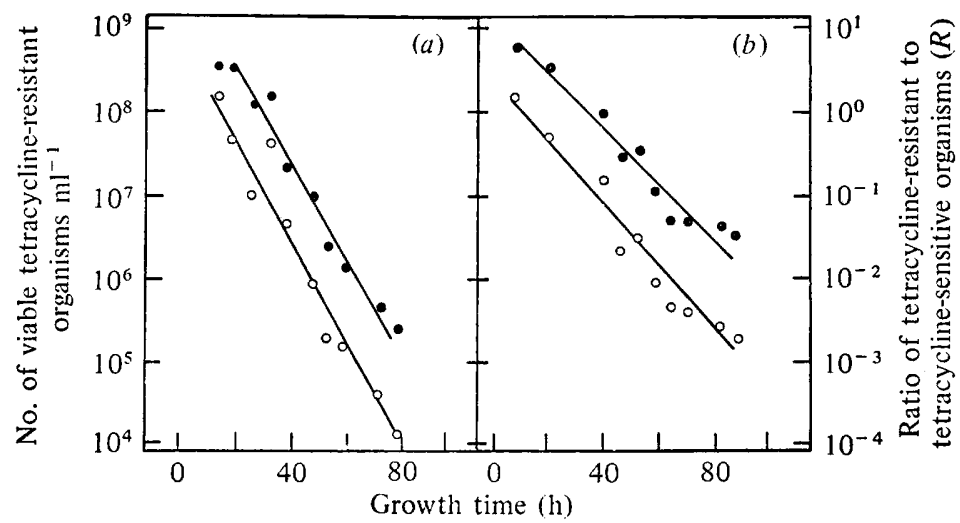

Fig. 4. Competition between $E$. coli $\mathrm{K} 12(\mathrm{TP} 120)$ and $E$. coli $\mathrm{K} 12(\mathrm{TP} 120 \mathrm{~A})$ in glucose-limited chemostats at dilution rates of $0.10 \mathrm{~h}^{-1}(a)$ and $0.35 \mathrm{~h}^{-1}(b)$. Number of viable tetracycline-resistant organisms [E. coli K12(TP120)] (O). Ratio of the number of tetracycline-resistant organisms [E. coli $\mathrm{K} 12(\mathrm{TP} 120)]$ to tetracycline-sensitive organisms [E. coli $\mathrm{K} 12(\mathrm{TP} 120 \mathrm{~A})](\Theta)$.

Table 3. Competition experiments between E. coli $\mathrm{K} 12(\mathrm{TP} 120)$ and E. coli $\mathrm{K} 12(\mathrm{TP} 120 \mathrm{~A})$ at different dilution rates in carbon-limited and phosphorus-limited chemostat cultures

\begin{tabular}{|c|c|c|c|c|}
\hline \multirow[b]{2}{*}{$\begin{array}{l}\text { Nutrient } \\
\text { limitation }\end{array}$} & \multirow{2}{*}{$\begin{array}{l}\text { Dilution } \\
\text { rate } \\
\left(\mathrm{h}^{-1}\right)\end{array}$} & \multicolumn{2}{|c|}{$\begin{array}{c}\text { Specific growth rate, } \mu \text {, of } \\
\text { uncompetitive population } \\
{[E \text {. coli } \mathrm{K} 12(\mathrm{TP} 120)]}\end{array}$} & \multirow{2}{*}{$\begin{array}{l}\text { Average percentage } \\
\text { decrease of } \mu \text { for } \\
\text { uncompetitive } \\
\text { population } \\
\text { [E. coli K12(TP120)] }\end{array}$} \\
\hline & & $\begin{array}{c}\text { From eqn 1 } \\
\text { (Jannasch, 1969) }\end{array}$ & $\begin{array}{c}\text { From eqn } 3 \\
\text { (Slater \& Bull, 1978) }\end{array}$ & \\
\hline $\begin{array}{l}\text { Carbon } \\
\text { (glucose) }\end{array}$ & $\begin{array}{l}0 \cdot 10 \\
0 \cdot 15 \\
0 \cdot 25 \\
0 \cdot 35\end{array}$ & $\begin{array}{c}-0.02(0) \\
0.05 \\
0.17 \\
0.27\end{array}$ & $\begin{array}{l}-0.03(0) \\
0.05 \\
0.17 \\
0.26\end{array}$ & $\begin{array}{r}100 \\
67 \\
32 \\
24\end{array}$ \\
\hline $\begin{array}{l}\text { Phosphorus } \\
\text { (phosphate) }\end{array}$ & $\begin{array}{l}0 \cdot 10 \\
0 \cdot 15 \\
0 \cdot 25 \\
0 \cdot 35\end{array}$ & $\begin{array}{l}0.01 \\
0.03 \\
0.16 \\
0.23\end{array}$ & $\begin{array}{l}0.02 \\
0.04 \\
0 \cdot 16 \\
0 \cdot 21\end{array}$ & $\begin{array}{l}85 \\
77 \\
36 \\
37\end{array}$ \\
\hline
\end{tabular}

significant during growth under substrate-limited conditions and submaximal specific growth rates. A detailed examination of the kinetics of competition between one pair of organisms differing in sensitivity towards tetracycline, namely $E$. coli K12(TP120) and E. coli $\mathrm{K} 12$ (TP120A), showed that under both carbon-limiting and phosphorus-limiting conditions, and at all the growth rates examined, the tetracycline-sensitive population always had a competitive growth advantage over the tetracycline-resistant population (Fig. 4; Table 3). In these experiments, care was taken to ensure that both the newly inoculated populations were growing exponentially before establishing continuous growth conditions. Thus, differences in the growth dynamics of the competing populations were ascribable to differences in growth parameters and were not obscured by additional factors such as variable lag phases or differences in physiological status. For all competition experiments, the removal of the uncompetitive tetracycline-resistant $E$. coli K12(TP120) followed the expected washout kinetics (Fig. 4). At the highest dilution rate examined $\left(D=0.35 \mathrm{~h}^{-1}\right)$ for carbon-limited competition, the percentage decrease in the specific growth rate of the uncompetitive parent population was similar to the difference between the maximum specific growth rates in closed culture (Tables 2 and 3). At the same dilution rate with phosphate as the growth-limiting substrate, the parent strain was even more uncompetitive since, with existing growth conditions determined by $E$. coli K12(TP120A), E. coli $\mathrm{K} 12$ (TP120) was only capable of a growth rate of $0.22 \mathrm{~h}^{-1}$ (Table 3 ). The degree 
of competitiveness between the two populations increased with decreasing growth rate of the successful population such that with glucose as the growth-limiting substrate at the lowest dilution rate examined the parent population was essentially washed out as a nongrowing population (Table 3).

\section{DISCUSSION}

The purpose of this study was to examine the behaviour of $E$. coli containing a plasmid coding for resistance to four drugs under growth conditions where the presence of the resistance mechanisms was unnecessary, that is in an environment which lacked any of the drugs. This situation is relevant to the distribution of drug-resistant organisms throughout the biosphere, particularly away from the selective environments which led to the evolution of resistant organisms, and it is important in assessing the environmental conditions which may influence the persistence of drug-resistant organisms and plasmid stability. In drug-free environments, the plasmid is redundant and environmental pressures could then discriminate against plasmid-containing organisms, since synthesis and replication of the plasmid utilizes elemental and energy resources which otherwise might be diverted to biomass production and a high population growth rate. This principle was demonstrated by Zamenhof \& Eichhorn (1967) who showed that amino acid auxotrophs of Bacillus subtilis had a marked growth rate advantage over isogenic prototrophic strains under carbon-limited growth conditions. Furthermore, the greater the number of biosynthetic sequences dispensed with by the auxotroph the greater was its growth rate advantage over the prototroph. Conversely organisms which wasted growth nutrients, for example, by overproducing and excreting an amino acid, were at a competitive disadvantage (Zamenhof \& Eichhorn, 1967; Baich \& Johnson, 1968).

In view of the strongly selective growth conditions occurring in chemostat continuousflow culture (Cox \& Gibson, 1974; Harder et al., 1977; Slater \& Bull, 1978) and the fact that there was a large difference between the specific growth rates of plasmid-containing and plasmid-minus strains of $E$. coli (Table 2), it was anticipated that mutant plasmidminus strains would have been rapidly selected for under nutrient-limited growth conditions. Our experiments showed that this was not the case and, indeed, in only one instance under phosphate-limited conditions after approximately $700 \mathrm{~h}$ growth - was a plasmidminus population detected. Thus the plasmid of $E$. coli K12(TP120) appeared to be considerably more stable than the $\mathrm{F}^{\prime} l a c$ plasmid in $E$. coli under lactose-limited growth conditions (Slater \& Bull, 1978). However, unlike the RP1 plasmid in E. coli strain W3110, which was stably maintained for up to $144 \mathrm{~h}$ growth under conditions of carbon, phosphorus or magnesium limitation at growth rates between 0.05 and $1.0 \mathrm{~h}^{-1}$ (Melling et al., 1977), plasmid TP120 was only partially stable. Particularly under phosphate-limited conditions, the cultures readily lost resistance to one or two drugs which suggested that the plasmid could partially fragment, perhaps producing a smaller plasmid, and hence gain an advantage in growth rate over the parent strain. Large multiple resistance plasmids seem to be formed as the result of the linkage of separately derived resistance genes or groups of genes to a basic replicating and transferring unit (RTF replicon) and this is a reversible process (Cohen, 1976). Clearly, this provides a mechanism for the generation of smaller plasmids by random reassociation without one (or more) of the original DNA segments and preliminary evidence suggests that this was the case here. The fact that tetracycline resistance was regularly lost indicated that this particular sequence was more readily excised from the original plasmid than the other resistance genes. At present we can offer no satisfactory explanation of the observation that the loss of drug resistances occurred more readily under phosphate-limited conditions than under carbon-limited conditions, particularly as the competition experiments between strains K12(TP120) and K12(TP120A) showed a greater growth rate difference under carbon limitation than under phosphorus limitation (Table 3). The loss of the autotransferring capacity in strains 
K12(TP120C) and K12(TP120D) also appeared to contribute towards a selective growth advantage either through the loss of the transfer genes or through a mutation resulting in the non-expression of the genes.

The competition studies with $E$. coli strains K12(TP120) and K12(TP120A) showed that putatively smaller plasmids, certainly carrying resistance genes for fewer drugs, in the mutant strain had a considerable growth advantage. Moreover, the lower the concentration of the growth-limiting substrate (that is, at low growth rates) the greater the difference between the mutant and parent growth rate potentials and the greater the advantage to be gained in losing part of the plasmid (Table 3). It is, however, difficult to explain why the removal of part of the plasmid or, indeed, the whole plasmid results in such large increases in the specific growth rate simply in terms of the conservation of limiting growth resources.

Finally, in all the selection experiments, some of which were continued for over $2000 \mathrm{~h}$ of continuous growth, very low levels of the uncompetitive plasmid-containing organisms were maintained. This is an observation in agreement with the experiments of Melling et al. (1977), although as a percentage of the population our residual resistant populations were several orders of magnitude lower. The reason for the persistence of these populations is not obvious since kinetic theory predicts that in open growth systems uncompetitive populations ought to be completely eliminated. Most probably these low levels are growth system artifacts representing a small population retained as a result, for example, of nonhomogeneous conditions within the culture vessel or wall growth. However, it cannot be excluded that some mechanism, so far unidentified, exists whereby low levels of a potentially advantageous capability (drug resistance) are retained within the population even though currently the population may be disadvantaged. Clearly, the long-term survival of the population subjected to future drug challenges would be greatly aided if a few members of the population retained the necessary resistance mechanisms.

D. G. was supported by a Research Studentship from the Medical Research Council. We are grateful to Professor D. C. Ellwood and Drs K. P. Flint, K. G. Hardy, H. Smith and G. Willshaw for helpful discussions and Mrs D. E. Sanders for valuable technical assistance.

\section{REFERENCES}

ANDERSON, E.S. (1975). Viability of transfer of plasmid from Escherichia coli $\mathrm{K} 12$ in the human intestine. Nature, London 255, 502-504.

ANDERSON, J.D. (1974). The effect of $\mathbf{R}$ factor carriage on the survival of Escherichia coli in the human intestine. Journal of Medical Microbiology 7, 85-90.

ANDERSON, J. D. (1975). Factors that may prevent transfer of antibiotic resistance between Gramnegative bacteria in the gut. Journal of Medical Microbiology 8, 83-88.

Anderson, J. D., Gillespie, W. A. \& Richmond, M. H. (1973). Chemotherapy and antibiotic transfer between enterobacteria in the human gastro-intestinal tract. Journal of Medical Microbiology 6, 461-463.

BAICH, A. \& JoHnson, M. (1968). Evolutionary advantage of control of a biosynthetic pathway. Nature, London 218, 464-465.

CoHen, S. N. (1976). Transposable genetic elements and plasmid evolution. Nature, London 263, 731738.

Cox, E. C. \& Gibson, T. C. (1974). Selection for high mutation rates in chemostats. Genetics 77, 169-184.
Davis, B. D. \& Mingioli, E. S. (1950). Mutants of Escherichia coli requiring methionine or vitamin $\mathrm{B}_{12}$. Journal of Bacteriology 60, 17-21.

Dennison, S. \& Baumberg, S. (1975). Conjugation behaviour of $\mathrm{N}$ plasmids in Escherichia coli K12. Molecular and General Genetics 138, 323331.

Freary, T. W., Sturtevant, A. B. \& Lawford, J. (1972). Antibiotic resistant coliforms in fresh and salt water. Archives of Environmental Health 25, 216-220.

Grabow, W. O. K., Prozesky, O. W. \& Smith, L. S. (1974). Review: drug resistant coliforms call for review of water quality standards. Water Research 8, 1-9.

Grindley, N. D. F., Humphreys, G. O. \& ANDERSON, E. S. (1973). Molecular studies of $\mathrm{R}$ factor compatibility groups. Journal of Bacteriology 115 , 387-398.

GRINSTED, J. \& LACEY, R. W. (1973). Ecological and genetic implications of pigmentation in Staphylococcus aureus. Journal of General Microbiology 75, 25-27.

Harden, P. \& MeYnell, E. W. (1972). Inhibition of gene transfer by antiserum and identification 
of serotypes by sex pili. Journal of Bacteriology 109, 1067-1074.

Harder, W., Kuenen, J. G. \& Matin, A. (1977). A review: microbial selection in continuous culture. Journal of Applied Bacteriology 43, 1-24.

HeRsheY, A. D. (1955). An upper limit to the protein concentration content of the germinal substance of bacteriophage T2. Virology 1, 108-113.

Hughes, C. \& MeYNell, G. G. (1975). High frequency of antibiotic resistant enterobacteria in the river Stour, Kent. Lancet ii, 451-453.

INSELBURG, J. (1978). ColE1 plasmid mutants affecting growth of an Escherichia coli recB recC $s b c C$ mutant. Journal of Bacteriology 133, 433-436.

JANNASCH, H. W. (1969). Estimation of bacterial growth rates in natural waters. Journal of Bacteriology 99, 156-160.

KAYAMA, A. M. \& YARA, T. (1975). Plasmid mutations affecting self maintenance and host growth in Escherichia coli. Journal of Bacteriology 122, 80-88.

LACEY, R. W. (1975). Antibiotic resistance plasmids of Staphylococcus aureus and their clinical importance. Bacteriological Reviews 39, 1-32.

Melling, J., Ellwood, D. C. \& Robinson, A. (1977). Survival of $\mathrm{R}$ factor carrying Escherichia coli in mixed cultures in the chemostat. FEMS Microbiology Letters 2, 87-89.
NaKazawa, T. (1978). Tol plasmid in Pseudomonas aeruginosa PAO: Thermosensitivity of self maintenance and inhibition of host cell growth. Journal of Bacteriology 133, 527-535.

Palchaudhuri, S. \& Chakrabarty, A. M. (1976). Isolation of plasmid deoxyribonucleic acid from Pseudomonas putida. Journal of Bacteriology 126, 410-416.

Slater, J. H. \& BulL, A. T. (1978). Interactions between microbial populations. In Companion to Microbiology, pp. 181-201. Edited by A. T. Bull \& P. M. Meadow. London: Longmans.

SMITH, H. W. (1970). Incidence in river water of Escherichia coli containing $\mathrm{R}$ factors. Nature, London 228, 1286-1288.

Terawaki, Y., Kakizawa, Y., Takayasu, H. \& YoshikAWA, M. (1968). Temperature sensitivity of cell growth in Escherichia coli associated with temperature sensitive R (KM) factor. Nature, London 219, 284-285.

Yokota, T., Kasuga, T., KaIfKo, M. \& Kuwahara, S. (1972). Genetic behaviour of $\mathbf{R}$ factors in Vibrio cholerae. Journal of Bacteriology 109, $440-442$.

ZAMENHOF, S. \& EICHHORN, H. H. (1967). Study of microbial evolution through loss of biosynthetic functions: establishment of 'defective' mutants. Nature, London 216, 456-458. 